\title{
Sustainable grain complex development of Russia: formation of grain clusters
}

\author{
E.P. Meleshkina, O.I. Bundina*, A.S. Khuhrin \\ VNIIZ - branch of Gorbatov research center for food systems, Moscow, 127434, Russia
}

\begin{abstract}
Human civilization is developing in the regime with aggravation and maximum aggravation in $2025-2030$. The development instability, the probability of not only unlikely - but also incredible events - global disasters, "Black Swans", has drastically increased. There are tectonic changes happening in nature and society. In these conditions, more than ever, the importance of the Concept of Sustainable Development has increased not only as a theoretical and intellectual message to the development of humanity in total turbulence, but above all, to practical implementation of this Concept. Firstly, the changes taking place affected agriculture of the countries of the world and Russia, and especially its grain complex. From the perspective of system-synergistic, bioeconomic, cluster and global approaches, the definition to the "sustainable development of the grain complex" concept was developed, the structure of its potential development, a set of measures to increase the grain complex development stability in the format of agroforestry clusters system creation was proposed. The cluster system formation will be a radical tool to increase the stability, efficiency, and competitiveness of Russia's grain economy, weaken global climate change and prevent disasters.
\end{abstract}

\section{Introduction}

The Earth and all mankind are developing in a mode with aggravation and maximum aggravation in 2025 - 2030 [1]. Development instability and its unpredictability has unprecedentedly increased. Global turbulence is being increased at micro, macro- and megalevels: hydrogen atom decreased by $5 \%$, DNA has changed, Schumann resonance frequency increased from $7.83 \mathrm{~Hz}$ to $36 \mathrm{~Hz}$, the solar system has moved into the area of very high energies, etc. In the words of physicists, there was a quantum transition, as a result, matter and all organics changed, the climate changed significantly, etc. This means that unpredictability has increased dramatically in agriculture and its development, the climate change is obvious - surprises shall be expected - the "Black Swans". These changes were imposed upon the negative effects of human activity: deforestation, drainage of marshland, the use of obsolete intensive farming technologies, etc. As a consequence, the great rivers of Volga, Dnepr, Lena, Ob' were swept away, many steppe rivers ceased to exist. In 2020, an unprecedented drought covered Krasnodar and Stavropol Krai, Rostov region and other grain regions, that is, the "core" of the grain complex of Russia focused on grain export. The

* Corresponding author: boi888@mail.ru 
problem of "aridity" has become one of the key ones. In these circumstances, the role and importance of practical implementation of sustainable development concept and the need to move from words to action increases. The global economic elite, represented by the founder of WEF Klaus Schwab, also places sustainability among the first priority. The problem of sustainable development and its various aspects are investigated by the scientific community [2-4]. It is especially relevant for the grain complex, which has been the main driver of the Russian economy in recent years.

The aim of the study was to develop a system of measures to increase the grain complex development stability in Russia in the conditions of the global systemic crisis, especially global climate change, ensuring the implementation of the target indicators of the Grain Development Strategy of the Russian Federation until 2035.

\section{Methods of research}

To obtain a more comprehensive picture of the country's grain complex development, the research was carried out from the position of system-synergistic, bioeconomic, cluster and global approaches.

System-synergistic approach involves the study of production, processing, and sale of grain as an organic whole, identification of positive and reverse links, self-organization processes of the grain complex and their usage to increase sustainability and efficiency.

Bioeconomic approach involves considering biotechnological processes in grain production and processing through the prism of biology and vice versa, since bioeconomic processes efficiency is eventually expressed in economic concepts and categories. This allows to fill the studies with deep meaning, see real processes "behind the numbers".

The cluster approach comes from the fact that clusters are a form of organization in society and nature (water clusters, clusters in chemistry, astronomy clusters, in economics, etc). It requires identification of really existing clusters and the formation of effective agroindustrial grain clusters. The formation of grain clusters is provided by the Strategy of grain complex development of the Russian Federation until 2035 [5].

The global approach requires research on the Russia's grain complex development in the context of the world economy dynamics and in connection with it. A special place is the study of a global problems set: "population growth, water, food, energy deficiency - ecology", grain needs.

\section{Results and discussion}

\subsection{The concept of "sustainable development of the grain complex"}

The World Commission on Environment and Development Report defines "sustainable development" as "development that meets the needs of the present but does not place the ability of future generations to meet their own needs under threat". It includes two key concepts:

- the concept of "needs"...;

- the concept of limitations imposed by the state of technology and the organization of society on the ability of the environment to meet current and future needs" [6].

In our opinion, this definition should be taken as a basic one as many countries have done, but to introduce certain country-specific, sectoral nuances that reflect the peculiarities of a particular complex system. At the global level, it is very difficult to define "sustainable development" accurately and exhaustively. We consider this definition as a frame, which only generally allows to state what is related to sustainable development. "A frame of any 
kind is the minimum structural information that uniquely defines a given class of objects" [7]. Therefore, the basic definition is logical and must be developed and supplemented in conformity with modern realities. Clarification is based on the judgment that "sustainable development" is based on the constant use and reproduction (preferably on an expanded scale) of "development potential", only in in this case the needs of future generations will be met. "Development potential" is a set of resources, means, opportunities required for sustainable development. "Development potential" is involuntarily associated with the concept of Shi or "situation potential" - the most refined and mysterious category of traditional Chinese strategy [8-9].

In this regard, we define the concept of "sustainable development" of the grain complex as follows.

Sustainable development of the grain complex is an actively managed socio-economic development that meets the increasing needs of present and future generations through the creation and utilization of renewable development potential with the preservation of natural ecosystems.

Potential can be divided into essential, natural - and therefore "free", and artificial potential to be paid for (mineral fertilizers, means of chemical protection, agricultural machinery, etc.). The structure of the grain complex development potential is shown in the figure. Since "development potential" must be replicated on an expanded scale, the potential's essence, its "core", should be bioeconomics.

In a broad sense, we understand bioeconomics as the socio-economic application of biological sciences' achievements to develop economic theory, methodology and practice [10].

In a narrow sense, bioeconomics means an economy in which biotechnology is the source of a significant share (and ideally $100 \%$ ) of economic output.

A critical element of development potential is "Science", since:

- it provides continuous generation of ideas and innovative technologies that generate unique competitive advantages;

- $\quad$ "Over 25 years, Israel increased agricultural production by 17 times. People don't understand, but agriculture is 95\% science and 5\% work," said President Shimon Peres [11.]

- The Cluster Manifest stressed the following: "The competitiveness of enterprises is no longer dependent on the cost ratio but is increasingly based on their innovation capacity, diversity and quality of their products. Since innovation drives growth and research is at the heart of innovation, the volume of research and development spending... is a determining factor in assessing the dynamism of industrialized countries" [12]. 


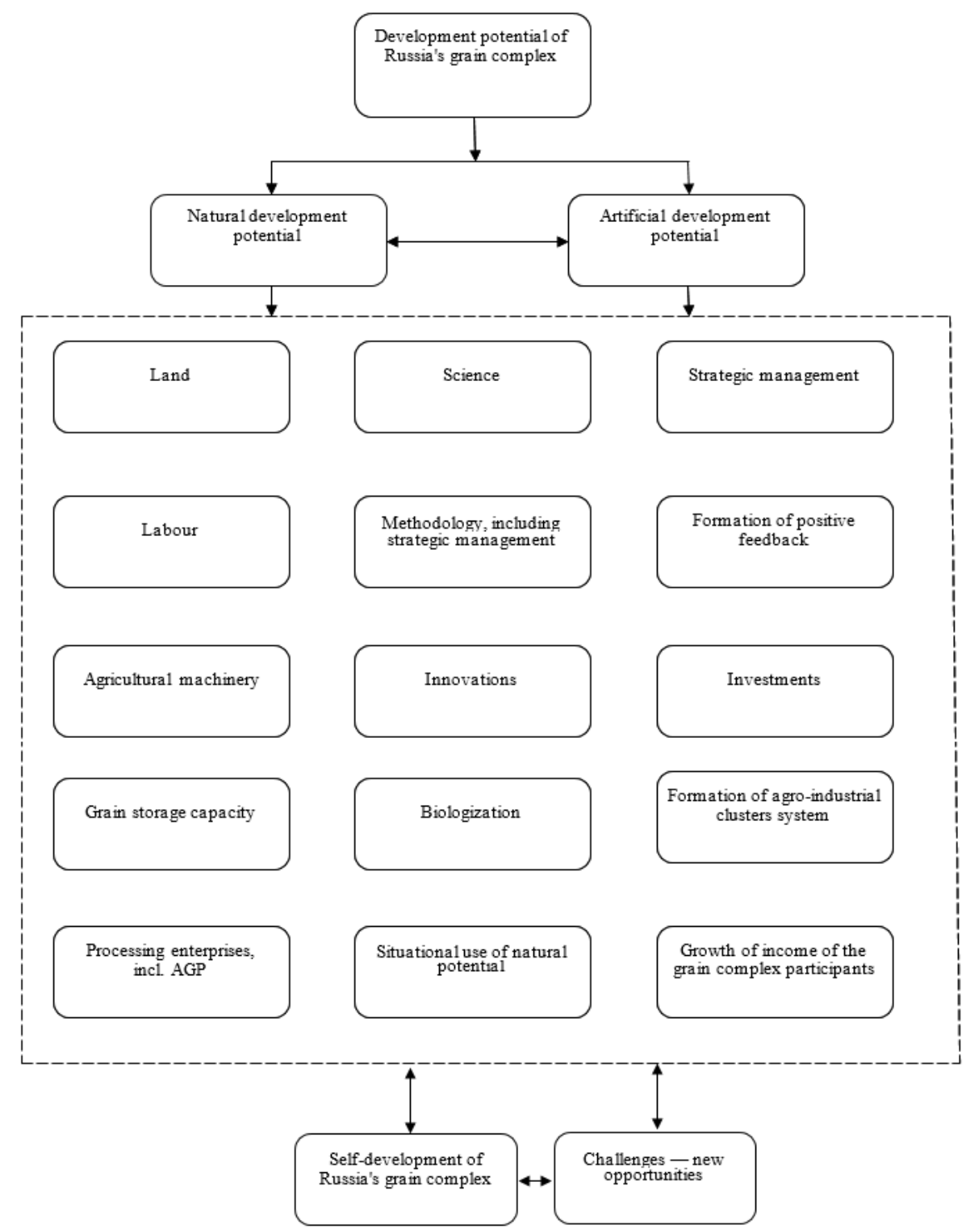

Fig. 1. Development potential of Russia's grain complex

- "In recent decades in the Russian Federation, the contribution of selection to the increase in yield is estimated at $30-70 \%$ and as negative trends of climate change increase, its role will increase." [5].

From the point of view of system-synergistic approach, the key factor for the sustainable grain complex development is the formation of positive reverse links, which, in turn, are mechanisms of accelerated self-development of complex systems that give rise to regimes with exacerbation. In the grain complex and agriculture, interlinks tend to be symbiotic. Such interlinks are:

- the link between crop production and animal husbandry. This is a natural link: crop production supplies feed and in return receives manure as a valuable organic fertilizer (cattle 
manure is especially valuable). In the main grain regions (Krasnodar and Stavropol Krai, Rostov region), this link is extremely weakened (the share of grain and leguminous crops in the cultivated area structure is within $65-78 \%$, compared to 1990 in 2018 , the share of feed crops in the cultivated area structure decreased by 3.7-9.4 times, and the number of cattle decreased by 3-3.5 times). As a result of obsolete intensive farming technologies usage, the following has decreased: soil fertility, efficiency of mineral fertilizers' usage; under the influence of the formed plow pan and soil degradation - moisture accumulation, water is not absorbed and strengthens erosion processes, moisture deficiency;

- $\quad$ symbiosis between plants and microorganisms in the rhizosphere is a fundamental symbiotic link. On average, $20-30 \%$, and sometimes $50 \%$ of all photosynthesis products are sent by the plants to microorganisms in the form of solutions of sugars and polysaccharide mixtures, organic acids, etc., and in return they receive the necessary mineral NPK nutrition and other micro and ultra elements. If there's a need for any nutritional elements $(\mathrm{Fe}, \mathrm{Mg}, \mathrm{Ca}$, $\mathrm{K}$, etc.), microorganisms are able to extract these elements from the soil matrix (sand, clay, etc.). Biologists believe that this is due to extremely effective enzymes [13], and physicists think it is a result of cold nuclear fusion or nuclear reactions in biological systems [14]. Nevertheless, the fact remains: in symbiosis with microorganisms, plants are able to receive any element from the periodic table. Symbiosis restoration between plants and microorganisms increases both plant productivity and soil fertility, reduces the need for mineral fertilizers and moisture deficiency;

- the link between science and agricultural production. Low level of science funding for almost 30 years, low profitability of grain production, high debt load of agricultural producers and finally the direction of former RAAS institutes towards basic research led to a sharp weakening of of science and practice interaction. Innovations of domestic science are extremely rare, and the scope of their application is limited.

The rupture or extreme weakening of these symbiotic links has largely led to soil degradation. For example, in the Stavropol Krai, from 1964 to 2016 soil fertility decreased under the influence of intensive technologies. As a result, the arable area with a humus content of more than $4 \%$ decreased by $2 / 3$. Currently, actual fertile land in the Stavropol region amounts to $0.1 \%$, low-fertile arable land is about $90 \%$.

The most important component of the development potential of Russia's grain complex is the provision of agricultural machinery. From 1990 to 2019 in Krasnodar, Stavropol Krai, Rostov region, the load of arable land in agricultural organizations per 1 tractor increased by 1.5-1.6 times, for 1 combine harvester - by 2,4-3,5 times. At the same time, these regions' energy capacities per 100 ha of cultivated area decreased by 1.5-1.6 times. With this supply of agricultural machinery, it is impossible to perform agrotechnical operations within optimal terms, which is one of the reasons for the fluctuations in yield and gross cereals collections by years, low grain quality, its damage by fungi and mycotoxins. As a result, Russia's AIC loses up to 20 million tons of grain per year due to the shortage of agricultural machinery [11].

Based on a brief components' consideration of the grain complex development potential of Russia, it can be argued that its stability increase potential is significant.

\subsection{Formation of Russia's grain clusters system}

Creation of grain agroforestry clusters system is a radical and comprehensive solution to the problem of increasing Russia's grain complex development stability, since:

- it covers the entire cycle of grain production and sale - from its cultivation to export of grain and products of its processing;

- it provides for the development and application of biotechnology system throughout the cycle of grain production and sale, ensuring an expanded reproduction of the grain 
complex development potential, firstly increasing soil fertility, solving the main problem moisture deficiency, preservation and improvement of the environment;

science is at the forefront of development, since in world practice clusters are innovative; as a rule, their core is formed by scientific organizations that create unique competitive advantages of clusters [12];

- includes forest bands and massifs that are similar to natural forests. They provide the "inclusion" of the forest biotic pump of atmospheric moisture. The latter creates an autonomous water cycle, which is completely independent of the surrounding external influences, solves the problem of moisture deficiency and the creation of a favorable local climate [15];

- $\quad$ will improve the quality of grain, since the reduction of grain quality is a systemic problem and is formed already in the process of grain crops growing, their harvesting, transportation, refinement, storage, and processing. Grain quality begins with healthy soil [16];

- weaken and even eliminate the negative impacts of climate change through the restoration and creation of artificial ecosystems that mimic natural ecosystems;

- $\quad$ in the end, this will lead to a growth of grain yields by at least $20-30 \%$, herbs - by more than 2 times, will ensure the sustainable receipt of gross grain collections at the level envisaged by the Strategy of Russia's grain complex development until 2035 and above [5];

- will create unique competitive advantages to the country's grain complex by, first of all, environmental friendliness and grain quality and will allow to move from price competition in the world market to "quality", increasing the income of all participants in the grain complex.

The grain agroforestry cluster means a network - a system of geographically concentrated complementary market subjects, various industries and activities (agricultural organizations, peasant farms, personal subsidiary farms, processing enterprises, scientific and educational institutions, development institutes, authorities, etc. .), ecosystems producing and creating conditions for efficient production, processing and sales of grain, products of its processing, as well as innovative products based on unique competitive advantages of location, application of science and technology.

In our opinion, the cluster system of Russia should include at least two complementary clusters, which we will conventionally designate as "South" (Krasnodar and Stavropol Krai, Rostov region) and "Siberia" (Novosibirsk, Omsk and Tyumen regions, Altai Krai). The first is focused on grain export, the second - on deep grain processing.

In the transportation structure, the average annual share of Krasnodar, Stavropol Krai and Rostov region for the period from 2015 to 2017 amounted to $24.9,17.9$ and $20.5 \%$ respectively - that is, three regions had $63.3 \%$ share in the structure during that period. Moreover, in the period up to 2035 , these regions should provide more than $44.1 \%$ of grain export. These facts provide a complete basis for the formation of a grain cluster involving these regions [5].

"Siberia" cluster has its own specificity - it is far away from ports, is located in the center of Russia, potential cluster participants produce the highest quality grain in the country, so it can be oriented for deep grain processing, as well as for grain exports to China. This cluster's bidirection contains a "balancer" that allows to provide the highest market prices and income to agricultural producers in case of adverse conditions changes of the Chinese market. Being located in the center of Russia, this cluster can effectively supply deep grain processing products.

These grounds are quite convincing for the creation of at least two grain clusters in Russia being complementary to each other. It is advisable to create a third grain cluster, which would be localized in the Central Federal District (Voronezh, Kursk, Lipetsk, Tambov, Belgorod regions), let us call it the "Center" cluster, which would be focused on the livestock 
development in Russia (in 2019, the number of cattle in the country reached a historic low of 18.1 million heads - even in the most difficult years of the Second World War, the number of cattle in Russia was more numerous) [17]. Simultaneously, it would serve as a backup cluster to increase exports of grain and its deep processing products.

\section{Conclusions}

Thus, the conducted research allows to draw the following conclusions in the theoretical and applied aspects of ensuring the sustainable grain complex development of Russia:

1.Sustainable grain complex development is understood as an actively managed socioeconomic development, ensuring the satisfaction of the increasing needs of present and future generations building and utilizing renewable development potential with the preservation of the natural ecosystem. The basis of sustainable development is bioeconomics.

2.The concept of sustainable development needs to be transformed into a Strategy because in practice the implementation of this Concept is far from human security needs: humanity continues suicide development destroying natural ecosystems, forgetting their descendants who would have to live on Earth, spawned the COVID-19 pandemic. The Sustainable Development Strategy should be based on system-synergistic, bioeconomic, cluster and global approaches that will provide a more holistic vision and global and local issues' solutions of sustainable development.

3.A radical and comprehensive solution to ensure the sustainable grain complex development of Russia, which contributes to unconditional achievement of the target indicators of the "Long-term grain complex development strategy of the Russian Federation until 2035" would be the creation of an agro-industrial clusters' system "South", "Center", "Siberia", which would compliment each other and, as a result of geographical dispersion, could be the guarantors of target indicators' implementation of Strategy 2035 under adverse climatic conditions.

4.The essence and the basis of sustainable grain complex development of Russia should be science, bioeconomics and the system of biotechnologies covering the whole grain complex by its application and eventually providing an enhanced reproduction of its development potential.

\section{References}

1. A.S. Khuhrin, O.I. Bundina, I.Yu. Agnayeva, Economics of agricultural and processing enterprises, 12, 11-23 (2016)

2. E. Bell, Building International Capacities for Sustainable Growth, 4 (1), 60-63 (2010)

3. S.N. Bobylev, World Economy and International Relations, 61 (3), 107-113 (2017)

4. K. Schwab, The Fourth Industrial Revolution, 288 (2020)

5. Long-term grain complex development strategy of the Russian Federation until 2035. URL: http://docs.cntd.ru/document/560974985 (access date: 15.01.2021).

6. Report of the World Commission on Environment and Development "Our Common Future" URL: https://www.un.org/ru/ga/pdf/brundtland.pdf (access date: 15.01.2021).

7. G.S. Pospelov, Introduction to the Russian edition of "Minsky M. Data Representation Frames" 154 (1975)

8. A.S. Khuhrin, O.I. Bundina, I.Yu. Agnaeva, N.P. Tolmacheva, Economics of agricultural and processing enterprises, 1, 56-62 (2014) 
9. A.S. Khukhrin, I.Yu. Agnaeva, N.P. Tolmacheva, O.I. Bundina, International Journal of Econometrics and Financial Management, 2 (4), 130-135 (2014)

10. O.I. Bundina, A.S. Khuhrin, Trends in the development of science and education, 62-10, 15-19 (2020)

11. R.V. Nekrasov, Report at the agronomic meeting in 2019. URL: http://astragrohim.ru/vserossijskoe-agronomicheskoe-i-agroinzhenernoe-soveshhanie (access date: 15.01.2021)

12. Manifest about clusters. Assembly of the Chambers of Commerce and Industry of France. URL: https://www.socium.com.ua/manifest (access date: 21.01.2016)

13. A. Markov, Birth of complexity. Evolutionary Biology Today: Unexpected Discoveries and New Questions, 580 (2015)

14. V.I. Vysotsky, A.A. Kornilova, Nuclear synthesis and transmutation of isotopes in biological systems, 302 (2003)

15. G.V. Gorshkov, A.M. Makarieva, Biotic forest pump of atmospheric moisture, its relationship to global atmosphere circulation and value for land water circulation, 49 (2006)

16. E.P. Meleshkina, Flour products, 10, 42-44 (2018)

17. Russian Statistical Yearbook 2019 URL: https://rosstat.gov.ru/folder/210/documen t/12994 (access date: 15.01.2021) 